\title{
DEL ÁMBITO ACADÉMICO AL COMERCIAL Arqueología Urbana en la Provincia de Valencia, España
}

\author{
FROM THE ACADEMIC TO THE COMMERCIAL SCOPE \\ Urban Archeology in the Province of Valencia, Spain
}

\author{
Irma Asón Vidal ${ }^{1}$ \\ irma.ason@arsesken.com \\ María del Mar Marín ${ }^{2}$ \\ mmarins@esp.upv.es
}

\section{RESUMEN}

Este trabajo presenta una reflexión sobre la transformación de la Arqueología de disciplina académica a actividad comercial, tomando como ejemplo la gestión de la arqueología urbana en la provincia de Valencia (España). Esta transformación se realizó sin planificación alguna por parte de los poderes públicos. La Arqueología Comercial surgió en virtud de un cambio normativo sobre la gestión del suelo ocurrido a mediados de los años 90 del pasado siglo, siguiendo las corrientes neoliberales tan en boga en Europa en aquella época. La crisis económica que se inició en España en el año 2008, puso de manifiesto la debilidad de este sector, uno de los actores importantes dentro de la gestión de la Arqueología Preventiva en España, poniendo en riesgo un sector económico, que genera empleo de calidad, así como la salvaguarda del Patrimonio Arqueológico, un bien finito y de altísimo valor social.

PALABRAS LLAVE: Gestión Arqueológica, Valencia, Patrimonio.

\footnotetext{
${ }^{1}$ Discente, Programa de Doctorado de Administración y Dirección de Empresas, Departamento de Economía y Ciencias Sociales, Facultad de Administración y Dirección de Empresas, Universidad Politécnica de Valencia.

${ }^{2}$ Departamento de Economía y Ciencias Sociales, Facultad de Administración y Dirección de Empresas, Universidad Politécnica de Valencia.
} 


\begin{abstract}
This paper presents a reflection on the transformation of Archeology from an academic discipline to a commercial activity, taking as an example the management of urban archeology in the province of Valencia (Spain). This transformation was carried out without any planning by the public authorities. The Commercial Archeology arose by virtue of a normative change on the management of the ground happened in the middle of years 90 of the past century, following the neoliberal currents so in vogue in Europe at that time. The economic crisis that began in Spain in 2008, showed the weakness of this sector, one of the important actors in the management of Preventive Archeology in Spain, putting at risk an economic sector, which generates quality jobs, as well as the safeguard of the Archaeological Heritage, a finite good with high social value.
\end{abstract}

KEY WORDS: Archaeological Management, Valencia, Heritage.

Como disciplina académica, la arqueología surge en el seno de las universidades durante el siglo XIX. En el caso de la arqueología urbana en Valencia, fue en la década de 60, cuando gracias el profesor Miquel Tarradell hubo una participación más activa del departamento de Arqueología de la Universidad en las ciudades. Las excavaciones arqueológicas llevadas a cabo por la universidad se ceñían a rescates puntuales de hallazgos casuales en ámbito urbano. Durante los años siguientes, con la expansión urbanística de las ciudades españolas se realizan gran cantidad de hallazgos arqueológicos fortuitos, tanto en la ciudad de Valencia como en otras ciudades de la provincia por ejemplo, Sagunto o Lliria. De este modo, Ante la necesidad de regular este fenómeno de expansión en las ciudades españolas que generó una especulación descontrolada con destrucción de una gran cantidad de patrimonio arqueológico, en 1985 se aprobó en España la Ley de Patrimonio Histórico Español, con el objeto de proteger, preservar y gestionar el Patrimonio del país siguiendo las directrices europeas. 
Con la instauración del modelo democrático, tiene lugar un proceso descentralizador surgiendo así el Estado de las Autonomías, por el que se comparten y delegan competencias en materia de gestión patrimonial a las comunidades autónomas. Bajo un marco legal común, la Constitución de 1978, la Ley de Patrimonio Histórico Español y el estatuto de autonomía correspondiente cada comunidad autónoma irá produciendo diferentes modelos de gestión y publicando normativas que varían los tratamientos del patrimonio arqueológico (Querol, Martinez, 1996).

En el caso de la Comunidad Valenciana la Ley 4/1998 de Patrimonio Cultural Valenciano que será modificada por la Ley 7/2004 y ésta a su vez por la Ley 5/2007 de modificación de la Ley anterior desarrolla exhaustivamente la relación de la gestión del patrimonio arqueológico con el impacto ambiental y con el planeamiento territorial. En el artículo 59 de la Ley 5/2007 se recoge la definición más completa de las actuaciones arqueológicas que necesitan autorización: prospecciones arqueológicas, excavaciones, estudios de arte rupestre, trabajos relativos a la arqueología de la arquitectura. Y añade las actuaciones que impliquen manipulación con técnicas analíticas de materiales arqueológicos, las actuaciones relativas a la consolidación y restauración arqueológicas y el estudio y documentación gráfica o de cualquier tipo de los yacimientos arqueológicos. Las actuaciones arqueológicas deberán ser autorizadas por la Conselleria competente en materia de cultura. La solicitud deberá contener un plano en el que se delimiten 
los límites de la zona objeto de la actuación, la identificación del propietario del terreno y un programa detallado de los trabajos que justifique su conveniencia e interés científico y cualificación profesional, determinada reglamentariamente, de la dirección y equipo técnico encargados de los mismos (artículo 60, Ley 4/1998).

Como resultado de este cambio normativo se crea una demanda que genera una actividad económica nueva. Toda una serie de profesionales liberales y de empresas que realizan intervenciones arqueológicas de urgencia: prospecciones, sondeos, excavaciones extensivas y seguimientos de obra, han transformado una actividad que se ceñía al ámbito académico y público (universidades u otras instituciones públicas) en una actividad comercial.

Se plantea, entonces, una serie de reflexiones, tanto científicas como prácticas, de la difícil transformación de una disciplina como la arqueología, surgida en el seno de la academia, en una actividad de carácter comercial.

Las actuaciones arqueológicas de urgencia que se realizan en ámbito urbano valenciano obedecen únicamente a movimientos económicos y responden a la documentación de los elementos patrimoniales que puedan existir en el subsuelo y que se verán afectados por los movimientos de tierra que generará la obra. No existe un proyecto científico global a nivel ciudad que aúne todas las intervenciones con el fin de responder a toda una serie de cuestiones o hipótesis planteadas previamente, que permitan conocer la evolución urbanística, 
económica o histórica de ciudad por lo que no se plantea la intervención multidisciplinar a no ser que la autoridad competente en materia de cultura así lo exija por tratarse de hallazgos muy relevantes. La ley en sí misma no determina que el promotor de las obras deba hacerse cargo de la financiación de estudios antracológicos, palinológicos, sedimentológicos etc, el único estudio que se realiza es el estudio del material cerámico, numismático y de vidrio con el único objetivo de obtener dataciones de las unidades estratigráficas y/o material arqueológico susceptible de musealización. Se recolectan los restos faunísticos de visu pero no se estudian.

En el caso de los restos humanos, no son obligatorios por ley los estudios paleo antropológicos a no ser que lo especifique la autorización de intervención arqueológica, aunque viene siendo una exigencia de facto. Tampoco existe ni obligación ni protocolos para realizar la toma de muestras para un posterior estudio en caso de presentarse la oportunidad de hacerlo. Las obligaciones del promotor de la obra son las que determina la ley ¿Quién debe financiar los estudios de las ciencias afines a la arqueología los cuales a nuestro juicio no deben dejarse de lado? ¿Debe depender del presupuesto general de la obra o debe ser financiado por la administración pública? 


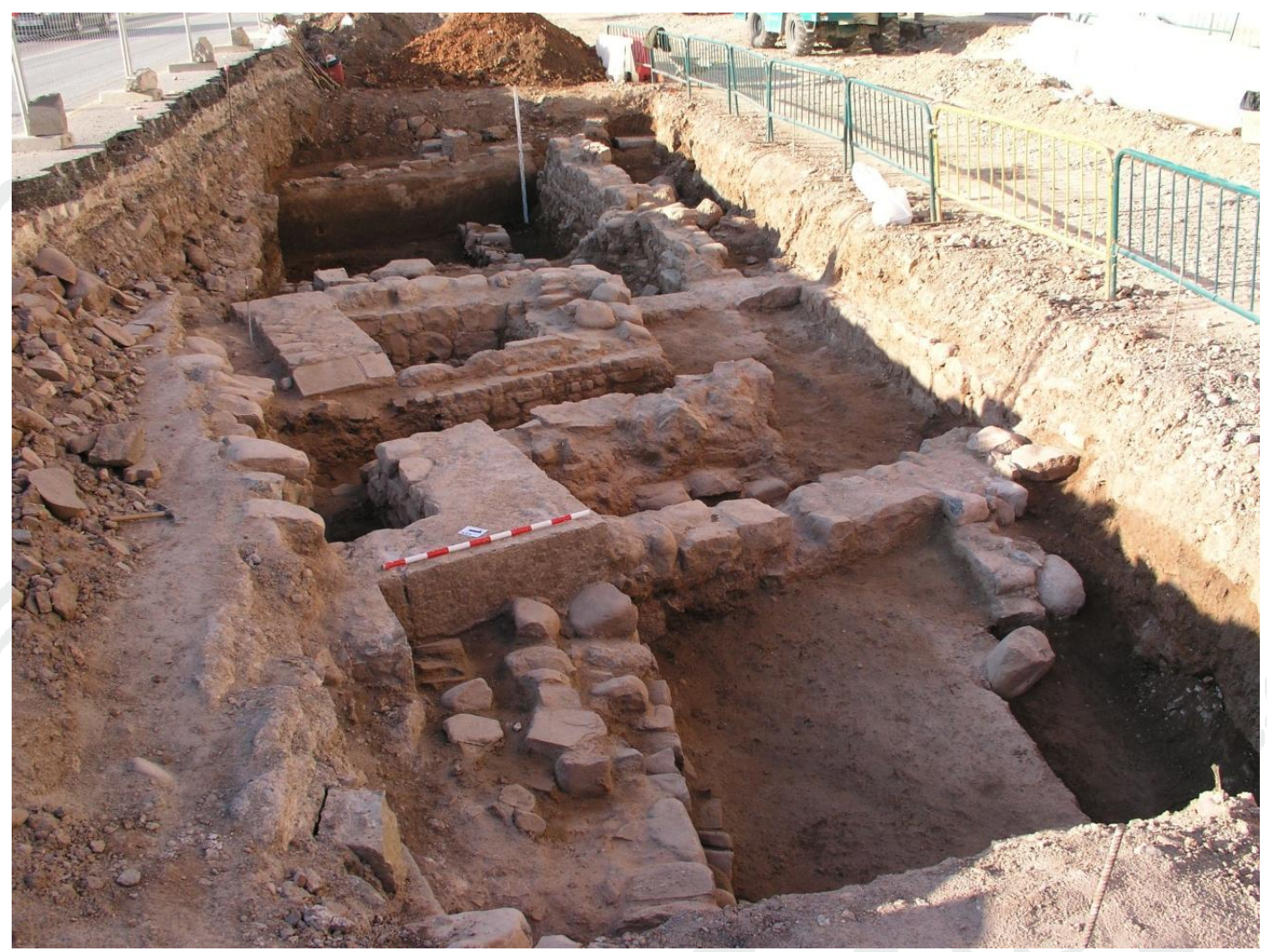

Figura 1. Intervención urbana de urgencia durante la remodelación urbana.

De no realizarse al menos el levantamiento de muestras estamos ante una merma en la información que pueda darnos una intervención arqueológica. Consideramos muy interesante que las ingentes cantidades de documentación en bruto generada en los últimos años pudiera ser procesada en colaboración con la Universidad que dispone de los medios materiales y humanos necesarios para el procesamiento del 
conjunto de informaciones que se pueden extraer en una intervención arqueológica y, de esta forma, generar un retorno reciproco ya que la empresa arqueológica puede además contribuir a la formación de nuevos profesionales.

Muchas veces, la academia no aprueba las estrategias de trabajo del arqueólogo empresario y pone bajo sospecha su labor aduciendo una falta de rigor científico. En realidad no se trata de una falta de rigor pues el método arqueológico es riguroso. Lo que ocurre en realidad es que una intervención de urgencia no tiene el mismo tratamiento que una excavación ordinaria en el seno de la universidad o de otra institución pública. En una intervención de urgencia se tiene en contra el factor tiempo y el factor promotor de la obra. Éste último no entiende ni quiere entender de objetivos científicos pero sí de costes y plazos que es justo de lo que no entiende la arqueología.

Se produce entonces una incoherencia: el promotor que financia la excavación arqueológica no desea que aparezcan restos por lo que el arqueólogo se enfrenta a la presión de quien tiene que pagarle, por el principio de "quien paga manda". El promotor sólo ve que le está costando dinero una actividad que no aporta nada a la obra y que además retrasa los plazos hayan o no restos arqueológicos. Por ejemplo en el transcurso de los seguimientos arqueológicos de obra civil (carreteras, gaseoductos, líneas eléctricas, urbanización nuevos espacios) es el arqueólogo el que se adapta al ritmo de la obra y no al contrario como debería ser. 


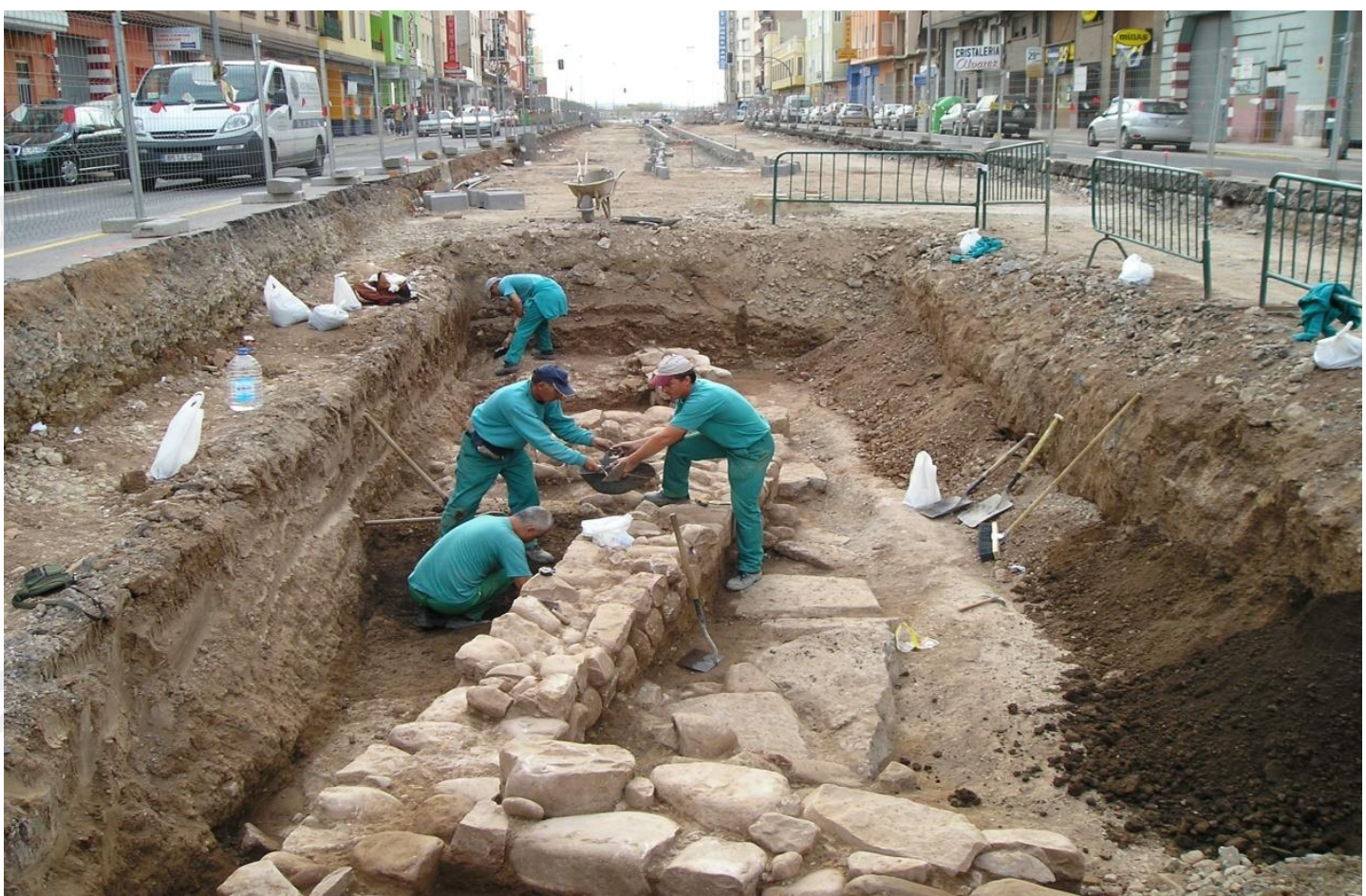

Figura 2. Excavación arqueológica de urgencia en remodelación urbana.

Por otro lado, tampoco existe un reglamento sobre calidad y cantidad del registro arqueológico y esto da lugar a la competencia desleal entre los propios arqueólogos lo que también acaba afectando al propio registro. No supone ni el mismo tiempo, ni el mismo coste documentar una necrópolis localizando los enterramientos con un punto geográfico y adjuntar una fotografía que realizar el dibujo arqueológico pormenorizado de cada enterramiento. Aquí entra la responsabilidad de la administración pública que debe juzgar si el registro 
arqueológico se ha realizado de forma correcta y de no ser así actuar en consecuencia.

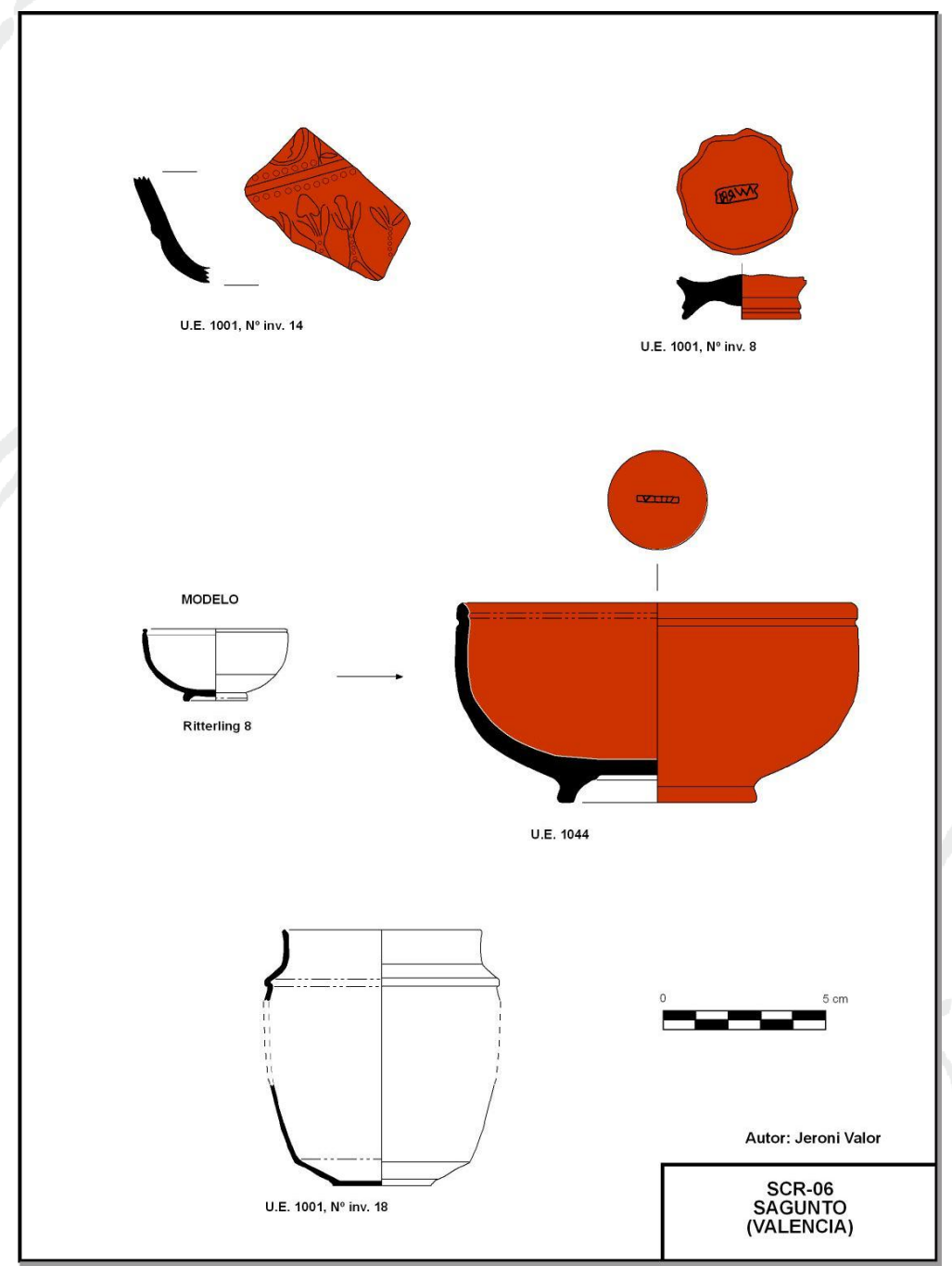

Indexadores: Latindex, ISIS, Google Academic
Figura 3. Ejemplo de lámina de materiales documentados en intervención arqueológica de urgencia en memoria científica. 
La dinámica de mercado conlleva una serie de consecuencias sobre el resultado científico. En estas circunstancias, se abandona el resultado científico a la buena voluntad del arqueólogo quien muchas veces cede su tiempo libre a la investigación y a la divulgación de los resultados de las excavaciones porque el promotor, de no verse obligado por la administración jamás financiará nada más allá de lo que obliga la ley. En estos momentos la legislación valenciana sólo obliga a la publicación de un resumen del informe preliminar de los resultados de la intervención. Por otro lado, la obligación de realizar una publicación extensa de los resultados de excavación obligaría a aumentar los honorarios de cada intervención arqueológica de salvamento.

El método de excavación que se utiliza con más frecuencia en las excavaciones urbanas que se realizan en la provincia de Valencia es el denominado método Harris, sistema de registro basado en fichas estandarizadas de Unidad Estratigráfica para la descripción de elementos y conjuntos, y el establecimiento de las relaciones estratigráficas existentes entre ellos. Asimismo, en el transcurso de los trabajos se realiza la secuencia estratigráfica documentada mediante el Matrix Harris. 
Figura 4. Ejemplo de planimetria de intervención urbana con método Harris.

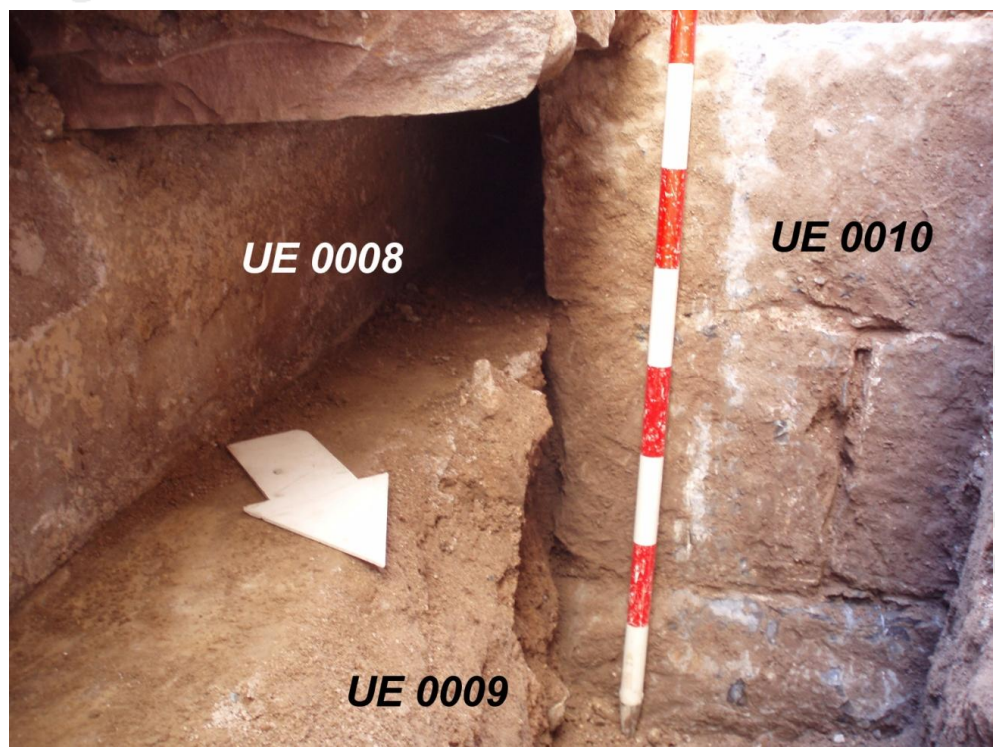

Figura 5. Ejemplo de documentación fotográfica de restos arqueológicos de intervención urbana con método Harris. 
La práctica de la arqueología de urgencia conlleva también una serie de consecuencias en cuanto a las técnicas de excavación, que no del método, causados por los plazos ajustados a los que suele obligar la obra. Ha sido necesario adaptarse a un trabajo con maquinaria pesada (retros, mini, giratorias etc...) sin que esto suponga un perjuicio para el patrimonio arqueológico. Hemos desarrollado, de esta manera, una técnica en intervenciones de salvamento, en terrenos de grandes dimensiones, de rebaje de estrato mediante cuchara de limpieza rebajando los estratos superficiales en capas de $20 \mathrm{~cm}$ hasta evidenciar elementos de naturaleza arqueológica. En ese momento se pasa a la excavación manual.

Los seguimientos de obra requieren también una forma de trabajar distinta puesto que la zanja no se excava con metodología arqueológica mientras no existan hallazgos. En el dibujo arqueológico también hemos tenido que innovar. Ha sido necesario combinar ortofotogrametría con herramientas topográficas de alta precisión topográficos (GPS de mochila) descartándose así la triangulación tradicional sobretodo en obras de gran extensión. Lo que agiliza la documentación en campo pasándose a dibujar en laboratorio a partir de herramientas informáticas, (formatos CAD SIG). 


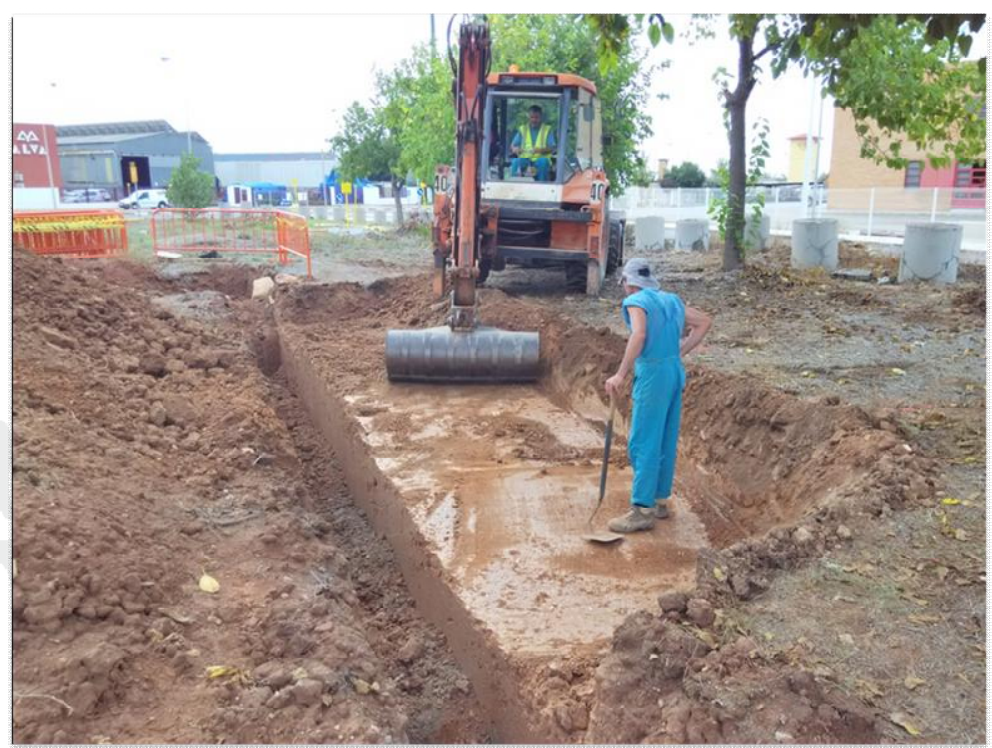

Figura 6. Trabajo arqueológico con maquinaria pesada.

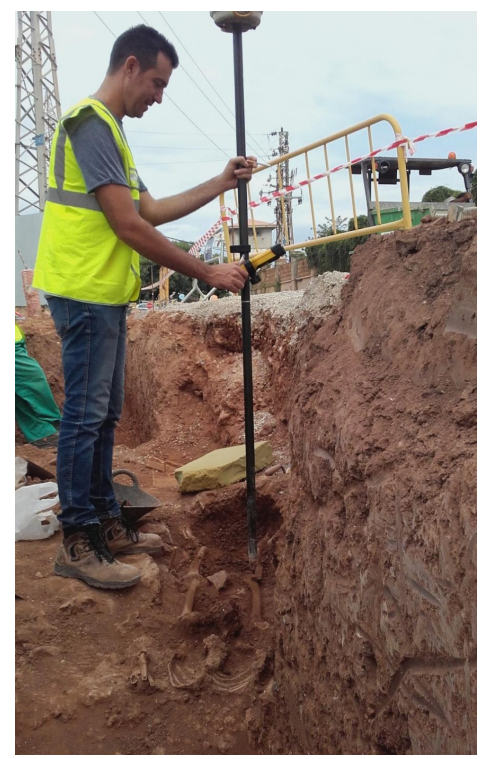

Figura 7. Posicionamiento en coordenadas absolutas de restos arqueológicos con GPS topográfico. 
Cual es en definitiva el papel de la arqueología Comercial? Adoptamos para este trabajo el término arqueología comercial definido por Criado Boado: La Arqueología Comercial es aquella actividad mercantil generada en relación con el Patrimonio Arqueológico, “cuando una gestión adecuada del mismo demanda la realización de actuaciones específicas que generalmente se desarrollan bajo contrato y, en todo caso, cumpliendo un determinado servicio y cobrando por él. Como es bien sabido, este campo está ocupado fundamentalmente por pequeñas empresas y "consultings" de arqueología” (Criado, 1996).

La arqueología comercial española es un claro ejemplo de oferta de Servicios Empresariales Intensivos de Conocimiento SEIC o Knowledge Innovation Business Services (KIBS) (Parga-Dans, 2011). Definidos como ciertos servicios industriales altamente innovadores con alto contenido tecnológico, los Servicios Empresariales Intensivos en Conocimiento (SEIC) se caracterizan por una gran dependencia del conocimiento profesional. También pueden ser fuentes primarias de información y conocimiento (informes, consultoría ...), o usar sus habilidades para producir servicios de intermediación para los procesos de producción de los clientes. Se han vuelto muy importantes en términos de competitividad al proporcionar conocimiento a las empresas y un diferencial en su sector (Miles et al., 1995).

Los SEIC son empresas que dependen del conocimiento o la experiencia de una disciplina específica (técnica) y proporcionan productos y servicios intermedios a 
menudo basados en el conocimiento (Escauriza et al., 2001). Como se mencionó anteriormente, la característica principal de los SEIC es que son altamente dependientes del conocimiento, por lo tanto, gran parte del valor de estas empresas será su Capital Intelectual. Para este trabajo hemos tomado la definición de Steward sobre Capital Intelectual como material intelectual, conocimiento, información, propiedad intelectual y experiencia que se puede utilizar para crear valor (Steward, 1997). La riqueza y el crecimiento en la economía actual son principalmente atribuibles al Capital Intelectual como el valor resultante de todos los activos intangibles (Edvinsson y Malone, 1997).

Existe una apreciación de que el conocimiento, constituyente común de la mayoría de los intangibles, es un recurso importante y un poderoso factor de producción. Los activos intangibles son no monetarios y sin sustancia física y deben utilizarse en la producción o suministro de bienes y servicios activos (García-Merino et al., 2010).

Los profesionales de la arqueología deberían estar encuadrados también encuadrados bajo el concepto de emprendedores sociales, más que empresarios tradicionales.

El emprendimiento social se asocia a la lucha contra la pobreza, el empoderamiento de los grupos vulnerables, la prestación de atención de salud o educación para los niños en los países pobres, la organización de centros de 
acogida para los sin techo, etc. En definitiva con el trabajo de las organizaciones no gubernamentales llenando el vacío institucional. Existe una creciente tendencia de investigación en los países en desarrollo que sugiere que cuando el gobierno no asume su papel en la creación y fortalecimiento de las instituciones sociales necesarias para que los mercados funcionen correctamente, los grupos empresariales deben intervenir en esta cuestión (Mair y Martí, 2006).

Más allá de esta primera acepción de emprendimiento social existen otras que englobarían cuestiones como la gestión/protección medioambiental, la gestión/protección de la cultura, y en el caso que concierne a este trabajo, la gestión/protección del patrimonio.

Cabe señalar, además, que las empresas dedicadas a la arqueología comercial posen características intrínsecas que las encuadran dentro del emprendimiento social.

El emprendedor social es aquel que entiende la búsqueda de beneficios únicamente como herramienta para asegurar el futuro de su empresa social y prácticamente sin que se note intentan cambiar cada día la mentalidad de la sociedad que les rodea, en el caso de la empresa de arqueología, respecto al Patrimonio Cultural. Una de las características diferenciales entre las ideas "empresariales" y las "sociales" es precisamente el hecho de que los emprendedores tradicionales parten con el objetivo de conseguir sus resultados 
"dentro" de la empresa, con ingresos y beneficios fácilmente medibles. El emprendedor social, en cambio, parte con el objetivo de conseguir sus resultados "fuera" de la empresa (en el mundo), en forma de impacto social, con o sin resultados económicos. Y el impacto "fuera" es siempre más complejo de medir que el impacto "dentro" de la compañía.

Una empresa de arqueología tiene como responsabilidad principal la correcta documentación del patrimonio cultural arqueológico, que va a ser destruido en el trascurso de las obras de implantación de algún tipo de infraestructura, y no el lucro en sí.

La arqueología comercial es una iniciativa empresarial generadora de valor para el bien común, que responde a una necesidad social como es la protección del patrimonio arqueológico como elemento de identidad cultural de una sociedad. Las sinergias establecidas entre las empresas de arqueología y sus clientes generan un contrapunto frente al emprendimiento destructivo meramente especulativo. Según Santos si estas empresas generan ingresos y cubren costes se denominan, entonces, emprendimientos sociales de mercado (Santos et al., 2013).

El descorazonamiento de los arqueólogos empresarios, comprometidos con el patrimonio arqueológico (hoy por hoy nadie elige la carrera de arqueología con la intención de ganar dinero) puede llevar al abandono de la profesión por lo que existe el riesgo de que la arqueología urbana acabe cayendo en manos de 
ingenierías y estudios de arquitectura cuyo único objetivo es salvar un trámite administrativo más, sin tener ninguna preocupación por generar conocimiento ni por salvaguardar el patrimonio arqueológico en beneficio de la colectividad.

La arqueología comercial, en una época de crisis como la que estamos viviendo ahora en España, en la que los recortes presupuestarios perjudican la financiación de excavaciones ordinarias en el seno de las universidades, se perfila como la mayor, y probablemente única, fuente generadora de documentación de restos de naturaleza arqueológica en los próximos años, contribuyendo a la creación de conocimiento, y por consiguiente a la protección del patrimonio arqueológico, y por tanto, debería tener un mayor apoyo de las instituciones públicas, administraciones y universidades, al fin y al cabo esta actividad surgió por la propia iniciativa pública.

No se trata de una actividad comercial fruto de una demanda espontánea de este servicio por parte de los agente económicos privados; sino que el marco normativo generado a partir de la legislación nacional, y sobre todo autonómico, en materia de patrimonio Cultural, es el que obliga a estos agentes económicos a demandar los servicios de arqueólogos profesionales, al no poder absorber la Academia el aluvión de peticiones de gestión de intervenciones arqueológicas en obras públicas y privadas. 


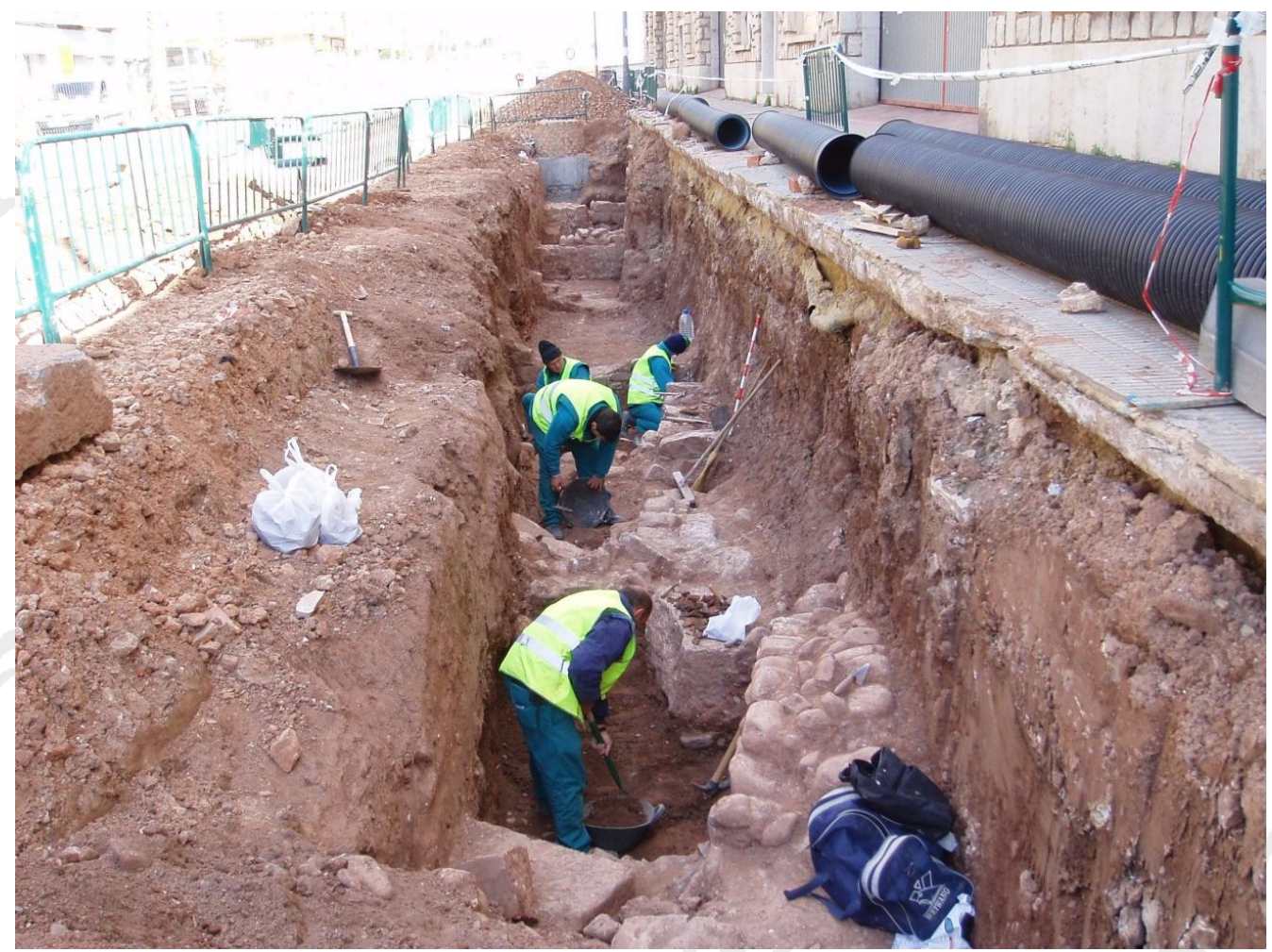

Figura 8: Excavación de urgencia en obra de infraestructura urbana.

Otro de los problemas con los que se enfrentan actualmente las empresas arqueológicas proveedoras de un servicio intensivo de conocimiento viene derivados de que la Administración subestimó el alcance de la norma; pues se vio desbordada por el boom inmobiliario acaecido en España, y sobre todo en la Comunidad valenciana, que generó un volumen desmesurado de intervenciones arqueológicas por lo que el trámite administrativo llegó a dilatarse en el tiempo hasta límites que hacían muy difícil plantear estrategias empresariales a medio y 
largo plazo, y que exasperaban al sector privado repercutiendo en la relación entre la empresa de arqueología y el cliente.

El descorazonamiento de los arqueólogos empresarios, comprometidos con el patrimonio arqueológico (hoy por hoy nadie elige la carrera de arqueología con la intención de ganar dinero) puede llevar al abandono de la profesión por lo que existe el riesgo de que la arqueología urbana acabe cayendo en manos de ingenierías y estudios de arquitectura cuyo único objetivo es salvar un trámite administrativo más, sin tener ninguna preocupación por generar conocimiento ni por salvaguardar el patrimonio arqueológico en beneficio de la colectividad. Consideramos que sería muy interesante que las ingentes cantidades de documentación en bruto generada en los últimos años pudiera ser procesada en colaboración con la Universidad y/o los museos de Arqueología, que dispone de los medios materiales y humanos necesarios para el procesamiento del conjunto de informaciones que se pueden extraer en una intervención arqueológica dentro de programas globales inter disciplinares y, de esta forma, generar un retorno reciproco ya que la empresa arqueológica puede además contribuir a la formación de nuevos profesionales.

En Valencia, deberíamos aprovechar la coyuntura económica actual para reflexionar y reconducir la disciplina hacia la optimización de sus resultados. Consideramos que no existen dos arqueologías, una académica y otra comercial; el objeto de estudio es el mismo y la finalidad también, es decir, generar 
conocimiento, aunque se haya ido olvidando por el camino. Para ello es necesario la implicación real de todos los agentes que intervienen en el estudio y la salvaguarda del patrimonio arqueológico: universidad, administración (sea estatal, autonómica o municipal, sin olvidar el papel relevante de los Museos arqueológicos que, en Valencia, dependen de la administración pública), profesionales y empresas para generar, entre todos, el marco ideal para un desarrollo de la actividad que garantice el máximo rendimiento de la investigación científica, su difusión y la protección del patrimonio arqueológico que, en ciudades con más de 2.000 años de historia como tienen muchas de las ciudades en la provincia de Valencia, contribuye, además, al desarrollo económico gracias a su atractivo turístico.

Cada actuación, sea de urgencia u ordinaria, es importante para el estudio de la evolución urbana de la ciudad en el transcurso de la Historia, para la protección, para la puesta en valor del patrimonio cultural y para contribuir al desarrollo económico y social de las ciudades. Desde un gran solar hasta una pequeña zanja para la instalación de una red de telecomunicaciones o de distribución de gas y agua potable, colectores, 1 tareas de mantenimiento periódico y/o averías que se produzcan en las mismas. Resulta necesario colocar a la Arqueología en el lugar destacado que se merece. Para ello todos los agentes implicados en esta disciplina generadora de conocimiento deben olvidar las diferencias y empezar a trabajar en un mismo sentido para generar una conciencia social sobre el patrimonio cultural similar a la que se viene generando desde el último tercio del siglo XX sobre 
ecología y la necesidad de proteger el medioambiente. De no ser así existe la posibilidad, cada vez menos remota, de que los intereses económicos, políticos y sus consecuentes presiones, acaben por generar una involución de la arqueología y de la protección del Patrimonio Cultural en general. Es decir, existe el riesgo de volver a lo meramente anecdótico del descubrimiento y al coleccionismo que busca la pieza por la pieza.

\section{BIBLIOGRAFÍA}

CRIADO BOADO, F. (1996): "El futuro de la Arqueología ila Arqueología del futuro?" Trabajos de Prehistoria vol. 53, nº 1, págs. 15-35.

EDVINSSON, L.; MALONE, M. (1997). Intellectual capital: realizing your company’s true value by finding its hidden brainpower. New York, NY: Harper Collins.

ESCAURIZA, M.; TINTORÉ, J.; TORRES, X. (2001): "Innovación en Servicios". Informe del proyecto "Innovación en el sector turístico balear. Análisis prospectivo de tecnologías" Proyecto financiado por la Fundación COTEC para la Innovación Tecnológica.

GARCÍA-MERINO J. D., G. ARREGUI, A. RODRÍGUEZ, A.; VALLEJO, B. (2010) motivos "externos" e "internos" para la valoración financiera de los intangibles: antecedentes y consecuentes. Investigaciones Europeas de Dirección y Economía de la Empresa, vol. 16, núm. 3. Academia Europea de Dirección y Economía de la Empresa España.

MAIR, J., \& MARTI, I. (2006). Entrepreneurship in and around institutional voids: A case study from Bangladesh. Journal of World Business, 41

MILES, I. ET AL. (1995). "Knowledge-Intensive Business Services: Users, Carriers and Sources of Innovation”. European Innovation Monitoring System. EIMS Publication, $\mathrm{n}^{\mathbf{0}}$ 15, Luxemburgo. 
PARGA-DANS, E.; VARELA-POUSA, R. (2011): ¿Caracterización socioeconómica de la Arqueología Comercial española. Resultados de la primera encuesta nacional dirigida a empresas del sectori. Revista Complutum, Vol. 22.

QUEROL, M. A.; MARTÍNEZ, B. (1996): La gestión del Patrimonio Arqueológico en España. Editorial Alianza Universidad Textos. 161. Madrid

SANTOS, F.; BARROSO, M.; GUZMÁN, C.; (2013) La economía global y los emprendimientos sociales. Revista de Economía Mundial. Vol. 35.

STEWARD, T.(2003): The Wealth of Knowledge: Intellectual Capital and the Twentyfirst Century organizations. Crown Pub Inc. 